\title{
Southern Egypt Stroke Study: Case Fatality Rates in a Hospital-Based Setting
}

\author{
G.H. Fawi ${ }^{1}$, F. Corea ${ }^{2, *}$, M.A. Abbas ${ }^{1}$, M.N. Thabit ${ }^{1}$, G. Comi $^{2}$ \\ ${ }^{I}$ Neurology Department, Sohag Faculty of Medicine, Sohag University, Sohag, Egypt and ${ }^{2}$ Unita Neurologica, Istituto di \\ Neurologia Sperimentale (INSPE), Istituto di Ricovero e Cura a Carattere Scientifico (IRCCS) San Raffaele, Milano, \\ Italy
}

\begin{abstract}
Background: The best approach to reduce the burden of stroke remains prevention. The large majority of epidemiological data available focus only on western countries. A better knowledge of stroke patients characteristics in Middle East and African communities will help to promote tailored campaigns by health care authorities and medical societies.

Objectives: to determine the characteristics of hospitalized stroke patients and case fatality in Upper Egypt governorates areas (Sohag, Quena, Aswan).

Methods: prospective hospital-based study carried out in the Neurology department of Sohag University hospital, involved 467 consecutive stroke patients. Demographic data, stroke-subtypes, risk factors, and stroke outcome, were analyzed. The study population was a consecutive series of patients admitted in the main tertiary health care level hospital of the area.

Results: hemorrhagic strokes reported in $37.5 \%$ of cases. Fifty six $\%$ were above 60 years and $8.6 \%$ were juvenile events. Sixty two $\%$ of stroke occurred in autumn-winter. Hemorrhagic stroke was higher in spring-summer (53\%). Hypertension was the more frequent risk factor reported in $42 \%$ of patients. In the study population smoking was present in $37.7 \%$, ischemic heart diseases in $32.8 \%$, dyslipidaemia in $29.5 \%$, Diabetes (DM) in $21.6 \%$, past history of stroke in $10.5 \%$, obesity in $10.1 \%$, positive family history for stroke in $9.6 \%$, atrial fibrillation in $6 \%$, Rheumatic heart disease (RHD) in $5.6 \%$ of patients and alcohol abuse in $1.3 \%$. The 1 -month case fatality rate was $27.8 \%$.

Conclusion: In Upper Egypt, we reported higher prevalences of hemorrhagic events, juvenile strokes and RHD compared with other studies.
\end{abstract}

\section{INTRODUCTION}

Stroke now ranks as the second leading cause of death and the first cause of morbidity allover the world. Among all the neurological diseases of adult life, stroke clearly ranks first in frequency and importance, at least 50\% of the neurological disorders in a hospitalized patients are of this type [13].

Despite advances in medical care of stroke and the advent of treatment of selected patients with acute ischemic stroke, prevention remains the best approach to reduce the burden of stroke. High-risk or stroke-prone individuals can be identified and targeted for specific interventions [4-6]. The prevalence of stroke is heterogeneous and is greater among the elderly and men and is variable from one region to another of the world [7]. Few data are available on Middle East and the developing countries of the African continent.

The aim of this survey was to study the characteristics of hospitalized stroke patients in upper Egypt, with regard to the relative prevalence of different stroke-subtypes, the

*Address correspondence to this author at the Unita Neurologica, Istituto di Neurologia Sperimentale (INSPE), Istituto di Ricovero e Cura a Carattere Scientifico (IRCCS) San Raffaele, Milano, Italy; Tel: +3902 2643 2813; Fax: +3902 2643 2951; E mail: corea.francesco@hsr.it demographic data and the prevalence of risk factors. A specific pattern of habits and demographic variables between genders is likely to be present in the study population (for religious and socio-economical reasons). The study enrolled all stroke patients admitted to the neurology departement of Sohag University Hospital during the study period.

\section{DEMOGRAPHY IN EGYPT}

Egypt is the most populated country in the Middle East and the second-most populous on the African continent, with an estimated 78 million people. Almost all the population is concentrated along the banks of the Nile (notably Cairo and Alexandria), in the Delta and near the Suez Canal. Egyptians can be divided demographically into those who live in the major urban centers and the fellahin or farmers of rural villages. The last 40 years have seen a rapid increase in population due to medical advances and massive increase in agricultural productivity.

Egyptians are by far the largest ethnic group in Egypt at $94 \%$ (about 72.5 million) of the total population. Ethnic minorities include the Bedouin Arab tribes living in the eastern deserts and the Sinai Peninsula, the Berber-speaking Siwis (Amazigh) of the Siwa Oasis, and the ancient Nubian communities living in cities in Lower Egypt and in villages clus- 
tered along the Nile in Upper Egypt. There are also tribal communities of Beja concentrated in the south-eastern-most corner of the country, and a number of Dom clans mostly in the Nile Delta and Faiyum who are progressively becoming assimilated as urbanization increases.

Egypt also hosts an unknown number of refugees and asylum seekers, but they are estimated to be between 500,000 and 3 million. There are some 70,000 Palestinian refugees, and about 150,000 recently arrived Iraqi refugees, but the number of the largest group, the Sudanese, is contested.

Egypt is divided into 28 governorates (in Arabic, called muhafazat). The governorates are further divided into regions (markazes). Sohag is the main tertiary health care level among the southern governorates (Sohag, Quena, and Aswan) (Fig. 1). Located about 72 miles south of Asyut, the City of Sohag is the capital of the Sohag governorate. It is also a major Coptic Christian center for Upper Egypt. Socioeconomic indicators show it to be the poorest or the second poorest governorate in Egypt on the basis of population pressure on land, illiteracy and infrastructure. A high proportion of rural households are either landless $(42 \%)$ or tenants with precarious tenancy contracts $(18 \%)$. The Governorate's total population reached 3 million in 1995, distributed in 461,600 households. The overall gender balance of the population suggests that out-migration has had little demographic impact, with $51 \%$ of the population male and $49 \%$ female. The rate of population increase is high at $2.7 \%$, or more than $0.5 \%$ higher than the national average. International agencies gives a rate of $2.8 \%$ annual increase in 1992 , showing a sig- nificant drop from the late $1980 \mathrm{~s}$, as it was $3.6 \%$ in 1987 and $3.1 \%$ in 1990 . Population density in the area is extremely high, with about 1,900 people $/ \mathrm{km} 2$, the highest being in Akhmeem district, with 2,805 persons $/ \mathrm{km} 2$ and the lowest in Dar as Salaam district with 1341 persons $/ \mathrm{km} 2$. The local hospital, is the main tertiary centre of the southern governatorates, having around 50 beds, admitting patients $24 \mathrm{hrs}$ a day, 7 days at week. The study population comes from the urban area of the city and rural ones of the above mentioned governatorates.

Health care facilities are limited in the rural areas. In the Governorate there are 149 rural health units, one school health unit, 35 health centers and 9 hospitals (admitting non selected patients). Although the overall number of health facilities in the Governorate is reasonable, existing facilities are primarily in the towns and many of them are insufficiently equipped, as well as lacking most basic supplies for much of the time. This lack of facilities and supplies is in a context of extremely high population density and a very low standard of hygiene, with canal water being used by children for playing and fishing, as well as by livestock and also often by women for laundry and dishwashing. The canal water carries whatever impurities have been dropped in the Nile from Uganda onwards. In this area no emergency transport system exist (i.e. 911), paramedical transport services are available but the large majority of patients reaches the medical centre with private means. In the study period the acute stroke unit was not available, and stroke patients were admitted in the large majority of cases in neurology wards. The main destination of patients at discharge was home, a small

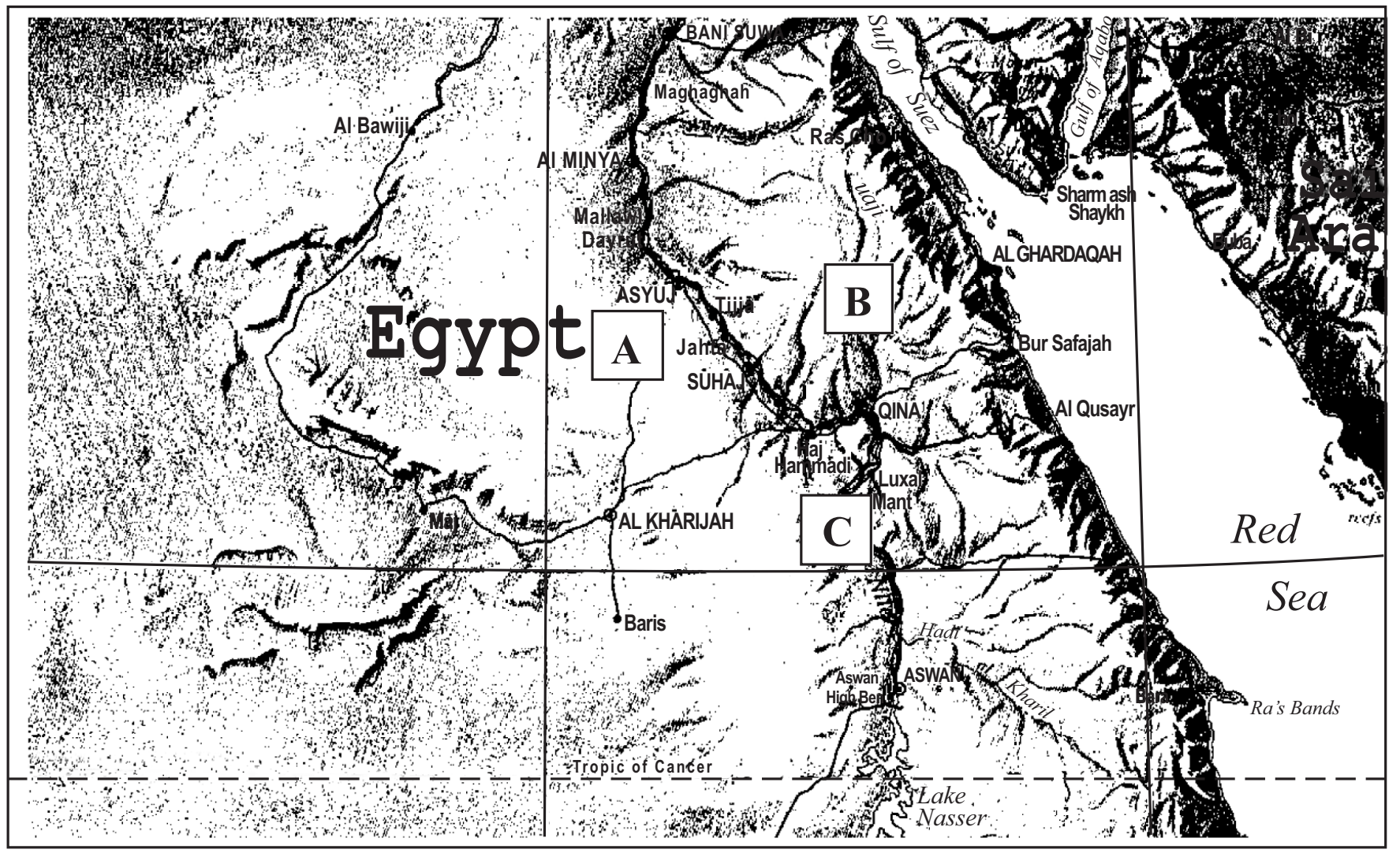

Fig. (1). Upper Egypt area and the 3 governatorates. A: Sohag; B: Quena; C: Aswan. 
number of subjects is referred to rehabilitation facilities/programmes. The study was designed to be a prospective hospital based study.

\section{PATIENTS AND METHODS}

The study involved 467 stroke-patients consecutively admitted in the Neurology department of Sohag University in the study period.

All patients of the study were subjected to the following:

*Detailed medical history interview

*Thorough general and neurological examinations

*Cranial computed tomography (CT) scanning using CT equipment Siemens, Somatom, HIQS, VB2 with tissue matrix $=256 \times 256$, one second scanning time and $10 \mathrm{~mm}$ slice thickness.

Stroke-subtype was diagnosed, and non-stroke patients were excluded.

*The following investigations were done to define risk factors:

- Electrocardiography \& Echocardiography to define relevant cardiac problems, history of myocardial infarction, coronary artery disease, congestive heart failure, arrythmia or valvular heart diseases.

- Blood sugar: Diabetes mellitus (DM), defined as venous plasma level of glucose $>7.0 \mathrm{mmol} / \mathrm{l}(>126 \mathrm{mg} / \mathrm{dl})$ or under hypoglycemic treatment.

- Complete lipogram: Dyslipidemia defined as venous plasma level of LDL cholesterol > $3.36 \mathrm{mmol} / \mathrm{l}$ (> 130 $\mathrm{mg} / \mathrm{dl})$ and/or Triglycerides $>1.8 \mathrm{mmol} / \mathrm{l}$ (>160 mg/dl).

- The following risk factors were defined:

- Arterial hypertension defined as systolic blood pressure $>140 \mathrm{mmHg}$, diastolic blood pressure $>80 \mathrm{mmHg}$ or antihypertensive treatment.

- Smoking: active smoking or not.

- Alcohol abuse active $>300$ gr/week.

- Over-weight, obesity: body mass index $\geq 27 \mathrm{~kg} / \mathrm{m}^{2}$

- Family history of stroke.

- Previous history of stroke or transient ischemic attacks (TIA).

- Education: > 6 years education-yes or no.

- Oral contraceptives use.

Follow-up: one month after stroke to define the vital outcome.

Statistical analysis: data coding and analysis using the SPSS 11.0 version were done, our resuls, were analysed using Odds Ratio, Risk limits, and $\mathrm{P}$ value.

\section{RESULTS}

Mean age at enrollment in the study populationwas 57.7 years, the median age was 60 years, range: 16 - 90 years. Hemorrhagic stroke prevalence was reported in $37.5 \%$ and infarction in $62.5 \%$. Fifty six \% were above 60 years and
$8.6 \%$ were below 46 years. Sixty two \% of stroke occurred in autumn-winter. Hemorrhagic stroke was higher in springsummer $(53 \%)$. Fifty seven $\%$ of stroke involved residents in rural areas. Hypertension reported in $42 \%$ of patients, more in males $59 \%$, more in > 40years $(97.4 \%)$, smoking in $37.7 \%$, ischemic heart diseases in $32.8 \%$, dyslipidaemia in $29.5 \%$, history of TIA in $23.1 \%$, DM in $21.6 \%$, past medical history of stroke in $10.5 \%$, obesity in $10.1 \%$, Positive family history of stroke in $9.6 \%$, atrial fibrillation in $6 \%$, RHD in $5.6 \%$ of patients and alcohol abuse in only $1.3 \%$ of cases.

At the univariate analysis the prevalence of juvenile events was found higher in the female gender $(11.5 \% \mathrm{vs}$ $6.2 \%)$. A peculiar seasonal trend was found: in springsummer the prevalence of hemorrhagic events reached the highest values with a $47.4 \%$ of the total. Regarding the educational level, those below 6 years of school more often suffered of an hemorrhagic event (Table 1).

Regarding demographics we found how smoking habit was more diffuse in the male gender ( $84 \%$ of smokers were males) while alphabetization was lower in female gender. Males had also more often a positive familiar history for vascular events (86\% vs 13.3). At the 1-month follow-up contact 130 subjects were dead, with a case fatality rate of $27.8 \%$ (Table 2).

The vascular risk factors were analyzed for age groups showing how DM was more diffused in older adults (21.6\%) like hypertension $(42.0 \%)$. Twenty-six patients had history of RHD, the $5.6 \%$ of the total. (Table 3 ).

\section{DISCUSSION}

Regarding stroke subtypes, we reported a high prevalence of hemorrhagic stroke $(37.5 \%)$. This proportion is one of the highest rates compared with other national studies, where in Ain shams (Cairo, Egypt) study [8-12], it was 22\% for hemorrhage and $75 \%$ infarction, also our result is still higher than most of the international results where in many European studies it was $83 \%$ for infarction and $17 \%$ for hemorrhage [13-17]. In non European surveys such as Japan it was found at $30.5 \%$ for hemorrhage and $69.5 \%$ for ischemic [18] also in China it was reported to be 12 up to $48 \%$ for cerebral hemorrhage [19]. It is well documented that the pathological patterns of stroke, stroke subtypes and stroke risk factors vary widely between racial groups (blacks, whites, hispanics), also these variations related risks may be related to environmental related risk factors or inherited risk factors [19-24]. The possible reasons for the higher incidence of cerebral hemorrhage in southern Egypt population in our study include the following, firstly, most of the populations in southern Egypt belongs to blacks, who usually carry a higher prevalence of hypertension. High prevalence of hypertension is reported in other studies [24, 25], in our study hypertension was found up to $55 \%$ in hemorrhagic stroke patients $\mathrm{p}<0.001 \%$ O.R. $>1.6$. Secondly, in southern Egypt, most of the populations are still following the traditional traits of marriage of related family members with potential consequence of inheritance of some of stroke related risk factors including hypertension, vascular malformations. Interestingly in our study we reported higher incidence of positive family history in our stroke patients $(9.6 \%)$, and $29 \%$ of those with positive family history were presented with cerebral hemorrhage and most of those hemorrhagic 
Table 1. Distribution of Stroke Subtypes and Demographic Differentials

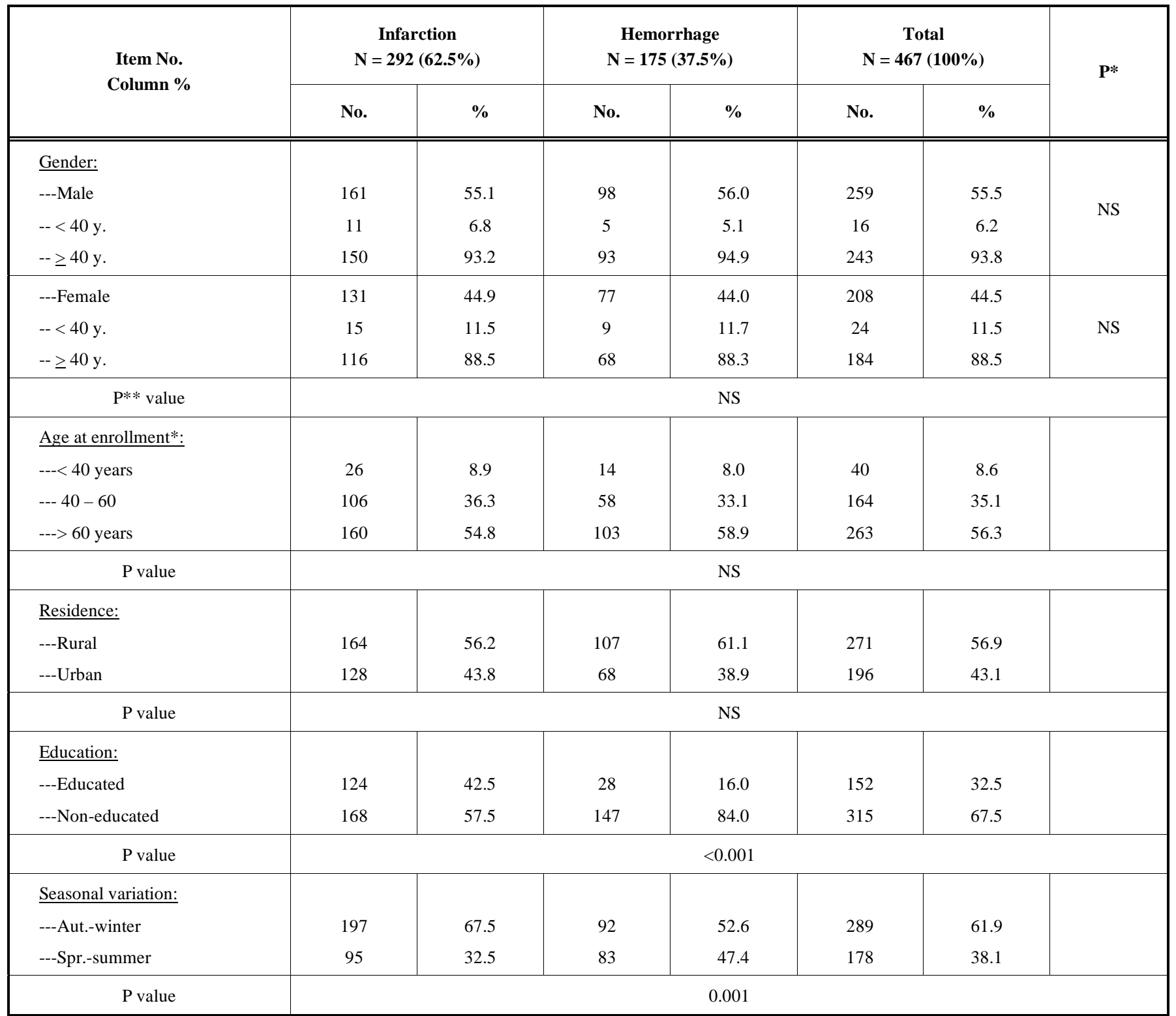

*NS = insignificant statistical difference. $\mathbf{P} *=$ statistical difference between sub-items, $\mathbf{P} * *=$ statistical difference between items.

Mean age at enrollment $=[57.7 \pm 12.9]$ years, the median $=60$ years, the infarction started at 16 years old while the hemorrhage started at 21 years of age.

strokes, their CT or MRI showed large lobar and/or intraventricular hemorrhage with great possibility of rupture of underlying vascular malformations. Previous reports stated that the site of hemorrhage shown on CT provides some clue to the cause, where hypertensive hemorrhage tend to occur slightly more in the basal ganglia, thalamus and pons, while lobar hemorrhage tend to be more often due to cerebral amyloid angiopathy, vascular malformations, and hemostatic failure [26, 27]. Also primary ventricular hemorrhage may be due more often to vascular malformation [28, 29]. Intracrainial vascular malformations are properly congenital or familial [30]. A few strokes are clearly familial in the studied population with a simple Mendelian pattern of inheritance of the underlying cause $[31,32]$.

Thirdly, the effect of the characteristic higher environmental temperature of southern Egypt, in this high tempera- ture climates, central nervous system dysfunction may occur including intracereberal hemorrhage, this dysfunction can be explained by a number of potential pathogenetic mechanisms including disidratation and rehydratation syndromes leading to tissue swelling and brain edema. In many critical weeks of the year the temperature rise over $40^{\circ} \mathrm{C}$. Temperature elevation its itself a threat for the central nervous system and to the body in general The excessive amounts of the released exitotoxic glutamets [33] may cause an encephalopathy, including seizures. Hemorrhages may occur in various organs including the brain. This are small lesions related to endothelial damage and disseminated intravascular coagulation. Areas showing maximal damage are cortex, thalamus and striatum.

Mortality rate in our study after one month was $27.8 \%$, this rate is higher than that reported by many other western 
Table 2. Demographic Data and Risk Factors Distribution According to Gender in the Study Population

\begin{tabular}{|c|c|c|c|c|c|c|}
\hline Item & $\begin{array}{c}\text { Total No. of } \\
\text { Cases }(\%)\end{array}$ & No. of Cases & Row \% & No. of Cases & Row \% & $\mathbf{P}$ \\
\hline \multicolumn{7}{|c|}{ Sociodemographic Data } \\
\hline Education & & & & & & \\
\hline +ve family history & $45(9.6 \%)$ & 39 & 86.7 & 6 & 13.3 & 0.000 \\
\hline Previous attack & $49(10.5 \%)$ & 32 & 65.3 & 17 & 34.7 & NS \\
\hline Obesity+ & $47(10.1 \%)$ & 16 & 34.1 & 31 & 65.9 & .001 \\
\hline Hypertension & $196(41.9 \%)$ & 115 & 58.7 & 81 & 41.3 & NS \\
\hline Ischemic H.D. & $153(32.7 \%)$ & 84 & 54.9 & 68 & 45.1 & NS \\
\hline Atrial fibril. & $28(5.9 \%)$ & 11 & 39.3 & 17 & 60.7 & NS \\
\hline Diabetes M. & $101(21.6 \%)$ & 50 & 49.5 & 51 & 50.5 & NS \\
\hline Rheumatic H. & $26(5.6 \%)$ & 8 & 30.8 & 18 & 69.2 & NS \\
\hline \multicolumn{7}{|c|}{ Outcome of the Cases at Discharge from the Hospital } \\
\hline Improvement & $337(72.2 \%)$ & 180 & 53.4 & 157 & 46.6 & NS \\
\hline
\end{tabular}

$* \mathrm{P}=\mathrm{NS}$, there were no statistically significant difference between strokers males and females as regard the the specified factor. Mean age of M (59.4 \pm 12.2$)$ was $>$ that of $\mathrm{F}(55.6 \pm$ 13.6) years. + Obesity = body mass index ( weight, $\mathrm{kg} /$ height, $\mathrm{m} 2)>30$.

Table 3. Age Groups, Risk Factors Distribution and Outcome in the Study Population

\begin{tabular}{|c|c|c|c|c|c|c|c|c|c|c|c|c|}
\hline \multirow{2}{*}{$\begin{array}{l}\text { Item No. } \\
\text { (column \%) }\end{array}$} & \multicolumn{2}{|c|}{ DM } & \multicolumn{2}{|c|}{ Hypertension } & \multicolumn{2}{|c|}{ IHD } & \multicolumn{2}{|c|}{$\mathbf{A F}$} & \multicolumn{2}{|c|}{ RHD } & \multicolumn{2}{|c|}{ Outcome } \\
\hline & - ve & $+\mathrm{ve}$ & - ve & $+v e$ & - ve & $+v e$ & - ve & + ve & - ve & $+\mathrm{ve}$ & Death & Improvement \\
\hline$<40$ years & 39 & 1 & 31 & 9 & 33 & 7 & 35 & 5 & 26 & 14 & 7 & 33 \\
\hline Total & 366 & 101 & 271 & 196 & 314 & 153 & 439 & 28 & 441 & 26 & 130 & 337 \\
\hline$\%$ from total & 78.4 & 21.6 & 58.0 & 42.0 & 67.2 & 32.8 & 94.0 & 6.0 & 94.4 & 5.6 & 27.8 & 72.2 \\
\hline $\begin{array}{l}\text { Odds Ratio* } \\
\text { Risk limits }\end{array}$ & \multicolumn{2}{|c|}{$\begin{array}{c}11.9 \\
1.7-236.5\end{array}$} & \multicolumn{2}{|c|}{$\begin{array}{c}2.7 \\
1.2-6.2\end{array}$} & \multicolumn{2}{|c|}{$\begin{array}{c}2.45 \\
1.0-6.2\end{array}$} & \multicolumn{2}{|c|}{$\begin{array}{c}0.4 \\
0.1-1.3\end{array}$} & \multicolumn{2}{|c|}{$\begin{array}{c}0.05 \\
0.02-0.14\end{array}$} & \multicolumn{2}{|c|}{$\begin{array}{c}0.52 \\
0.21-1.28\end{array}$} \\
\hline
\end{tabular}

studies, where in Malmo, Sweden it was $15 \%$ [9] in the Oxford shire Community Stroke Project it was $19 \%$ [15] and in Umbria Italy, it was $20.3 \%$ [34], however some other studies reported similar results as in the U.K. it was $31 \%$ [16] and in Australian study it was $24 \%$ [35].
These variations may be due to and explained by the followings, our study is a hospital based study which usually includes most of the severe stroke patients not the mild ones. The low awareness in the community, regarding stroke warning signs, and the poor scholarization accounts for big 
delays in the arrival of patients in the hospital, when the natural history of the disease may be hardly modifiable. Moreover most of stroke risk factor e.g. DM, hypertension, TIAs, were usually unchecked, untreated, and so were more prevalent and intense in most of our non-scholarized stroke patients.

Stroke mortality, as expected, was higher in hemorrhagic strokes $42.3 \%$ vs $19.2 \%$ in ischemic strokes. Stroke patients with DM carried mortality rate of $34.7 \%$, followed by those with AF $32.1 \%$, then hypertension $31.1 \%$, IHD $28.8 \%$ while in those with RHD carried mortality rate of $15.4 \%$, in stroke patients with two or more of the previous risk factors, the mortality rate reached more than $40 \%$. Mortality rate in our stroke patients above 46 years of age was $29 \%$, much higher than that in the juvenile stroke group $(17.5 \%)$ [36, 37]. Mortality of males was $30.5 \%$, while in females was $24.5 \%$ in all age groups also these results agree with literature data [38, 39].

Hyperlipidemia reported more in ischemic strokes but with no definite relationship with stroke subtypes. TIAs were reported more in ischemic strokes, more in older subjects. Alcohol consumption was reported in only the $1.3 \%$ of subjects, as expected. Obesity was reported more in females and more in ischemic strokes.

This study was limited to some extent in that it was not undertaken among the general population. However, as more than $80 \%$ of patients with acute stroke are hospitalised in this urban area of Sohag, major sampling bias was considered to be unlikely. Other limitations were due to the difficulties faced in a developing country, such as, likely selection bias due to care/deaths at home, referral patterns, case selection, missing data, and information bias due to errors in diagnosis or risk factor information.

The accuracy of diagnosis of stroke type (ischaemic or haemorrhagic) was satisfactory in the present study, since brain CT scan was performed in all individuals. Our hospital-based data probably well represent the situation in the Upper Egypt population in general because all acute medical cases are admitted to tertiary hospitals.

In general, age and hypertension are the most important risk factors for incidence of stroke in the developing world. In the study population, the prevalence of both ischaemic and hemorrhagic stroke rises within the age groups. Other factors such a diabetes mellitus and high lipid levels, was less relevant in this study.

Despite the availability of cost-effective intervention there are significant gaps, in primary prevention of cerebrovascular diseases, in low- and middle- income areas such as southern Egypt. Mostly there is a need to facilitate the access to preventive drug therapy and to promote healthy life-styles. Tailored policies are also required to promote clinical prevention, strengthen infrastructures of health-care facilities and providing continuing medical education for the personnel.

\section{REFERENCES}

[1] Norrving B, Lowenhielm P. Epidemiology of stroke in lund-orup Sweden 1983-85, incidences of first stroke and age-related changes in subtypes. Acta Neurol Scand 1988; 78: 413.
[2] Warlow CP. Introduction. Handbook of neurology. Oxford: Blackwell 1991.

[3] Adams RJ, Brambilla D. For the STOP investigators. Stroke prevention trial in sickle cell anemia (STOP). Proceedings of the $21^{\text {st }}$ annual meeting of the national sickle cell disease program, Mobile, AL 1996; p.19.

[4] D' Agostino RB, Wolf PA, Belanger AG, et al. Stroke risk profile adjustment for antihypertensive medications: The framingham study. Stroke 1994; 25: 40-3.

[5] Gillum RF, Sempos Ct. The end of the long-term decline in stroke mortality in United States? Stroke 1997; 28: 1527-9.

[6] Brown RD, Whisnant JP, Sicks JD, et al. Stroke incidence, prevalence, and survival: secular trends in Rochester, Minnesota, through 1989. Stroke 1996; 27: 373-80.

[7] Howard G, Evans GW, Pearce K, et al. Is stroke belt disappearing/ An analysis of racial, temporal, and age effects. Stroke 1995; 26:1153-8

[8] Whisnant JP. Effect of hypertension on carotid and vestibular TIAs. Ann Neurol 1978; 3(2): 107-15.

[9] Jerntrop P, Berglund G. Stroke registry in Malmo, Sweden. Stroke 1992; 23: 357-61.

[10] Bamford J, Sandercock P, Dennis M, et al. A prospective study of acute cerebrovascular disease in the community: The Oxfordshire community stroke project 1981-1986. Methodology, demography and incident cases of first-ever stroke. J Neurol Neurosurg Psychiatry 1988; 51: 1373

[11] Lindenstrom E, Boysen GD, Nyboe J, Appleyard M. Stroke incidence in Copenhagen, 1976-1988. Stroke 1992; 23: 28-32.

[12] Hany Aref, Hana N, Aida Sh. Stroke Unit-Ain Shams University year 2002 July-September. Egypt Stroke J 2003; 1 (1).

[13] Sivenius J, Heinonen OP, Pyorala K, Salonen J, Riekkinen P. The incidence of stroke in the Kuopia area of East Finland. Stroke 1985; 16(2): 188-92.

[14] Aho K, Reunanen A, Aromaa A, Knekt P, Maatela J. Prevalence of stroke in Finland. Stroke 1986;17(4) : 681-6.

[15] Bamford J, Sandercock P, Dennis M, Burn J, Warlow C. A prospective study of acute cerebrovascular disease in the community: The Oxfordshire Community Stroke Project 1981-1986. Incidence, case fatality rates and overall outcome at one year of cerebral infarction, primary intracerebral and subarachnoid hemorrhage. J Neurol Neurosurg Psychiatry 1990; 53: 16-22.

[16] Kalra L, Perez I, Melbourn A. Stroke risk management. Changes in Mainstream Practice. Stroke 1998; 29: 53-7.

[17] Peter L, Kolominsky-Rabas MD, Margarete Weber MD, et al. Epidemiology of ischemic stroke subtypes according to TOAST criteria. Stroke 2001; 32: 2735.

[18] Suzuki K, Kutsuzawa T, Takito T. Clinico-epidemiologic study of stroke in Akita, Japan. Stroke 1987; 18: 402-6.

[19] Chung DM. Cloning of fibrinogen genes and their C-DNA. Ann NY Acad Sci 1994; 408: 449-52.

[20] Broderick J, Brott T, Kotheri R, et al. The Greater Cincinnati/Northern Kentucky Stroke Study: preliminary first ever and total incidence rates of stroke among blacks. Stroke 1998; 29: 41521.

[21] Sacco RL, Boden-Albala B, Gan R, et al. Stroke incidence among white, black, and Hispanic residents of an urban community; the Northern Manhattan Stroke Study. Am J Epidemiol 1998: 147: 259-68.

[22] Gorelick PB. Cerebrovascular disease in African Americans. Stroke 1998: 29: 2656-64.

[23] Rosamond WD, Folsom AR, Chambless LE, et al. Stroke incidence and survival among middle-aged adults: 9-year follow-up of the Atherosclerosis Risk in Communities (ARIC) cohort. Stroke 1999; 30: 736-43.

[24] Giles WH, Kittner SJ, Hebel JR, et al. Determinants of black-white differences in the risk of cerebral infarction: the National Health and Nutrition Examination Survey Epidemiologic Follow-up Study. Arch Intern Med 1995; 155: 1319-24.

[25] Gillum RF. Stroke mortality in blacks; disturbing trends. Stroke 1999; 30: 1711-15.

[26] Schutz H, Bodeker RH, Damian M, et al. Age-related spontaneous intracerebral hematoma in a German community. Stroke 1990; 21: 1412-18.

[27] Molinari GF. Lobar hemorrhages. Where do they come from? How do they get there? Stroke 1993; 24: 523-6. 
[28] Gates GC, Barnett HJM, Vinters HV, et al. Primary intraventricular hemorrhage in adults. Stroke 1986; 14: 808-10.

[29] Darby DG, Donnan GA, Salling MA, et al. Primary intraventricular hemorrhage: clinical and neuropsychological findings in a prospective stroke series. Neurology 1988; 38: 68-75.

[30] Nabros MW, Azzam CJ, Albanna FJ, et al. Delayed postoperative dural arteriovenous malformations. Report of two cases. J Neurosurg 1987; 66: 768-72.

[31] Natowics M, Kelley RI. Mendelian etiologies of stroke. Ann Neurol 1987; 22: 175-92.

[32] Liao D, Myers R, Hunt S, et al. Familial history of stroke and stroke risk. The Family Heart Study. Stroke 1997; 28: 1908-12.

[33] Young GB, Allan HR, Charles FB, et al. Coma and impaired consciousness: A clinical prespective. USA: McGraw-Hill 1998; pp. 209-16.

[34] Ricci S, Celani MG, La Rosa F, et al. SEPIVAC: A communitybased study of stroke incidence in umbria, Italy. J Neurol Pyschiatry $1991 ; 54: 695-8$.
[35] Simons LA, McCallum J, Friedlander Y, Simons J. Risk factors for ischemic stroke: Dubbo Study of the elderly. Stroke 1998; 29: 13416-6.

[36] Bonita R, Stewart A, Beglehole R. International trends in stroke mortality: 1970-1985. Stroke 1990; 21: 989-92.

[37] Li SC, Schoenberg BS, Wang CC, et al. Cerebrovascular disease in the people's Republic of China. Epidemiology and clinical feature. Neurology 1985; 35: 1708-13.

[38] Chang CC, Chen CJ. Secular trend of mortality from cerebral infarction and cerebral hemorrhage in Taiwan, 1974-1988. Stroke 1993; 24: 212-18.

[39] Fratiglioni L, Massey EW, Schoenberg DG. Mortality from cerebrovascular disease, international comparisons and temporal trends. Neuroepidemiology 1983; 2: 101-16.

(C) Fawi et al.; Licensee Bentham Open.

This is an open access article licensed under the terms of the Creative Commons Attribution Non-Commercial License (http: //creativecommons.org/licenses/ by-nc/3.0/) which permits unrestricted, non-commercial use, distribution and reproduction in any medium, provided the work is properly cited. 